\title{
DESAFIOS E PERSPECTIVAS DO ESTUDANTE COM DEFICIÊNCIA VISUAL NA EDUCAÇÃO SUPERIOR: ANÁLISE DA PRODUÇÃO CIENTÍFICA
}

\author{
DESAFÍOS Y PERSPECTIVAS DE LOS ESTUDIANTES CON DISCAPACIDAD \\ VISUAL EN LA EDUCACIÓN SUPERIOR: ANÁLISIS DE LA PRODUCCIÓN \\ CIENTÍFICA
}

\section{CHALLENGES AND PERSPECTIVES OF STUDENTS WITH VISUAL IMPAIRMENT IN HIGHER EDUCATION: ANALYSIS OF SCIENTIFIC PRODUCTION}

\author{
José Aparecido da COSTA ${ }^{1}$ \\ Rosely dos Santos MADRUGA ${ }^{2}$ \\ Alexandra Ayach ANACHE ${ }^{3}$ \\ Eladio SEBASTIAN-HEREDERO ${ }^{4}$
}

RESUMO: A inclusão do estudante com deficiência visual na educação superior ainda tem sido desafiadora para os gestores e professores, para garantir êxito acadêmico. Mesmo com a existência de iniciativas e investimentos por parte do poder público, mas elas ainda são insuficientes diante das dificuldades de acesso e permanência destes universitários. Portanto, o objetivo deste trabalho é analisar as pesquisas sobre acesso e permanência, com ênfase no Atendimento Educacional Especializado de estudantes com deficiência visual nas produções da Revista de Educação Especial da Universidade Federal de Santa Maria (UFSM) no período de 2014 a 2019. Utilizamos uma análise quanti-qualitativa de natureza de revisão da produção científica na revista em questão, para isso trabalhamos com os indicadores deficiência, deficiência visual, educação superior, acesso, permanência, atendimento educacional especializado e suas combinações. A pesquisa resultou em 519 artigos, dos quais apenas 39 abordam a inclusão na educação superior. Foram selecionados 14 para análise, tratando de deficiência visual, educação superior, inclusão e permanência. Concluímos que o número de estudantes com deficiência visual na Educação Superior tem aumentado mais de 50\% (cinquenta por cento), que existe um conjunto de legislação que favorece a inclusão, porém não aparecem ainda as condições, seja de recursos/tecnologias ou de formação de professores para sua efetivação, conforme as pesquisas. $\mathrm{O}$ atendimento educacional especializado, garantido por lei, ainda não se percebe materializado. As publicações são relevantes para a criação de novas políticas, ações e estratégias para a permanência do estudante com deficiência na educação

${ }^{1}$ Universidade Federal de Mato Grosso do Sul (UFMS), Campo Grande - MS - Brasil. Doutorando no Programa de Pós-Graduação em Educação. Gestor de ações sociais da Secretaria de Estado de Trabalho e Assistência Social. ORCID: http://orcid.org/0000-0002-8603-0563.

${ }^{2}$ Universidade Federal de Mato Grosso do Sul (UFSM), Campo Grande - MS - Brasil. Mestre em Educação pelo Programa de Pós-Graduação em Educação Técnica em Assuntos Educacionais. Membro do Grupo de Pesquisa Educação Especial e Desenvolvimento Humano. ORCID: https://orcid.org/0000-0002-3596-6900. E-mail: rstsmadruga@gmail.com

${ }^{3}$ Universidade Federal de Mato Grosso do Sul (UFMS), Campo Grande - MS - Brasil. Professora Titular e Coordenadora do Programa de Pós-graduação em Psicologia. Doutorado em Psicologia Escolar (USP). ORCID: https://orcid.org/0000-0002-7937-4448. E-mail: alexandra.anache@gmail.com

${ }^{4}$ Universidad de Alcalá (UAH), Madri - Espanha. Professor Visitante Estrangeiro (UFMS). Doutorado em Educação (UAH) - Espanha. Pós-Doutorado em Educação (UNESP). ORCID: http://orcid.org/0000-0003-02934395. E-mail: eladio.sebastian@gmail.com

RPGE- Revista on line de Política e Gestão Educacional, Araraquara, v. 24, n. esp. 2, p. 1118-1136, set. 2020. e-ISSN: 1519-9029 
superior e atendimento educacional especializado de acordo com suas especificidades, mas que ainda necessitam de maiores aprofundamentos.

PALAVRAS-CHAVE: Educação especial. Deficiência visual. Educação superior. Inclusão.

RESUMEN: La inclusión de estudiantes con dificultades de visión en la educación superior todavía es un desafio para los gerentes y docentes para garantizar el éxito académico. A pesar de las iniciativas e inversiones del gobierno, todavía son insuficientes ante las dificultades de acceso y permanencia de estos universitarios. Por lo tanto, el objetivo de este trabajo es analizar las investigaciones sobre acceso, permanencia con énfasis en Apoyo Educativo Especializado para estudiantes con discapacidad visual en las producciones de la Revista de Educación Especial de la Universidad Federal de Santa María (UFSM) en el periodo de 2014 a 2019. Trabajaremos con un análisis cuanti-cualitativo en la revisión de la producción científica de la revista en cuestión, para ello se trabaja con los descriptores de discapacidad, discapacidad visual, educación superior, acceso, permanencia, apoyo educativo especializado y sus combinaciones. La búsqueda resultó en 519 artículos, de los cuales solo 39 abordan la inclusión en la educación superior. Se seleccionaron 14, para su análisis, centrados en discapacidad visual, educación superior, inclusión y permanencia. Concluimos que el número de estudiantes con discapacidad visual en Educación Superior se ha incrementado en más del $50 \%$ (cincuenta por ciento), que existe un conjunto de ordenanzas legales que favorecen la inclusión, pero las condiciones, ya sea de recursos / tecnologías o de formación, aún no aparecen en las prácticas de los profesores, según las investigaciones. El apoyo educativo especializado, garantizado por ley, aún no se realiza en todos los casos. Las publicaciones son relevantes para la creación de nuevas políticas, acciones y estrategias para la permanencia de los estudiantes con discapacidad en la educación superior y el apoyo educativo especializado según sus especificidades, pero que aún requieren mayor estudio.

PALABRAS CLAVE: Educación especial. Discapacidad visual. Educación universitaria. Inclusión.

ABSTRACT: The inclusion of students with visual impairments in higher education has still been challenging for managers and teachers to ensure academic success. Despite the investment initiatives by the government, but they are still insufficient in the face of the difficulties of access and permanence of these students. Therefore, the objective of this work is to analyze research on access and permanence with an emphasis on Specialized Educational Assistance for students with visual impairments in the productions of the Special Education Journal of the Federal University of Santa Maria (UFSM) in the period from 2014 to 2019. We used a quantitative-qualitative analysis of the nature of reviewing scientific production in the journal in question, for this we work with the indicators of disability, visual impairment, higher education, access, permanence, specialized educational assistance and their combinations. The search resulted in 519 articles, of which only 39 address inclusion in higher education. 14 were selected for analysis, dealing with visual impairment, higher education, inclusion and permanence. We conclude that the number of visually impaired students in Higher Education has increased by more than 50\% (fifty percent), that there is a set of legislation that favors inclusion, but the conditions, whether of resources/technologies or teacher formation, do not yet appear for its effectiveness, according to research. Specialized educational assistance, guaranteed by law, is not yet perceived as materialized. Publications are relevant for the creation of new policies, actions and strategies for the permanence of students with disabilities 
in higher education and specialized educational assistance according to their specificities, but it still need further study.

KEYWORDS: Special education. Visual impairment. Higher education. Inclusion.

\section{Introdução}

A expansão da educação especial teve um crescimento muito grande nos últimos anos e, dentro dela, o que concerne ao acesso de estudantes com deficiência visual nas universidades brasileiras também. No ano 2014 de acordo com dados do Censo da Educação Superior (INEP, 2014) registra-se 19.654 alunos com deficiência e de acordo com o último censo cadastrado no site do Instituto Nacional de Estudos e Pesquisas Educacionais Anísio Teixeira (INEP, 2018) no ano de 2018 esse número foi ampliado para 27.048 estudantes. O crescimento, em média 51,3 por cento. Na esteira desse movimento histórico, se constata por meio da averiguação de pesquisas por um lado, a ampliação de serviços calcados nas diretrizes e princípios contidos na educação inclusiva, como o concurso para Tradutores e intérpretes em Libras, a criação de laboratórios de educação especial para o atendimento educacional especializado aos estudantes com deficiência, a reserva de vaga em 2016 destinada as universidades públicas federais, os materiais adaptados, maquinas braile, linhas braile, a obrigatoriedade de acessibilidade nos sites universitários, enfim, uma gama de serviços, atendimentos e produtos destinados a esses estudantes.

Em termos de lócus temporal, na busca da concretização do escopo anunciado nesta produção, se traz o fato correspondente ao primeiro estudante cego que concluiu o Ensino Superior, como gênese comprobatória de tal acesso e permanência, estudante este de nome Walkírio Ughini Bertoldo, conforme Selau e Damiani (2014). Na ocasião, Bertoldo necessitou contratar um secretário para que realizasse as leituras, precisou também adquirir uma máquina de datilografia e, ainda, teve que viabilizar a importação de gravador de voz dos Estados Unidos. Portanto, naquele ponto da história, se constata que o ingresso de Walkirio na PUC/Rio Grande do Sul na realidade dependeu de iniciativa de ordem genuinamente meritocrática. Assim, o levantamento procedido com o fito de produzir o presente artigo, se encontra ancorado na busca de se explicitar as ações enfocadas a partir do conjunto de leis que trata da questão, assim como as inovações tecnológicas que, tem impactado na construção fática, relativa ao acesso do estudante com deficiência visual no Ensino Superior.

Deficiência é entendida na perspectiva social, como uma construção social, histórica, e assim uma limitação que ocorre na relação do sujeito com o seu meio social. Esse entendimento 
contrapõe a perspectiva médica que a compreende como a falta de estrutura, órgãos e funções. (FRANÇA, 2013). A deficiência visual nessa perspectiva é um impedimento sensorial que pode reduzir a participação da pessoa na sociedade, esse fato ocorre devido as barreiras que essa sociedade impõe, quer seja física, arquitetônica, pedagógica, enfim, obstáculos que impossibilitam a pessoa com deficiência a usufruir de todas as possibilidades de desenvolvimento.

A Inclusão é um princípio que foi sendo consolidado na década de 1990 com as Declarações Mundial de Educação para Todos (1990) e a Declaração de Salamanca (1994). Ao realizarmos o levantamento das publicações dos artigos que abordam temáticas situadas na área dos estudos consoantes à pessoa com deficiência no âmbito da educação superior na Revista de Educação Especial de Santa Maria, RS, se faz necessário inserir, enquanto referência histórica, os períodos nos quais esse público mereceu menções nas Escrituras Sagradas, a tratativa centrada na dicotomia eliminação versus permissão à vida a partir da piedade cristã, caso da Idade Média, de acordo com os estudos efetivados por Caiado (2006), Jannuzzi (2006), Mazzotta (2005) e Neres e Corrêa (2008). Pela mesma linha com fulcro em fatores históricos, também não se pode deixar de se referir aos movimentos mais recentes baseados na integração e inclusão das pessoas com deficiência.

Depreende-se, com relação ao acesso do mencionado contingente populacional, que temos os muitos documentos de cunho legal, cuja finalidade é dotar as instituições de ensino superior, de estrutura física e de recursos, tendentes a assegurar o acesso, permanência e progressão do acadêmico com deficiência visual na referida etapa de ensino. Propõe-se que todos e todas possam aprender juntos, desde que as condições de acesso, permanência sejam proporcionadas para que os estudantes com características específicas possam obter êxitos na aprendizagem, e assim concluírem os seus cursos. Para além dos mecanismos legislativos, e com relação ao acesso e permanência destes estudantes se constata a evolução de possibilidades a partir da Tecnologia (BIZELLI; SEBASTIAN-HEREDERO, 2016), de maneira que dentre estas, podem ser enfatizadas as assistivas, o advento dos programas leitores de tela, a ampliação das impressoras braile na esfera dos serviços públicos, os aplicativos com interface acessível inseridos em celulares, conversores de textos para áudio, a exemplo do Balabolka, o display braile, escâneres digitais com voz, dentre outros produtos. Nesse artigo a compreensão de tecnologia assistiva está de acordo com Lei $\mathrm{N}^{\circ}$ 13.146, de 6 de julho de 2015 (BRASIL, 2015).

A perspectiva teórica Histórico Cultural subsidiou a pesquisa em curso sobre acesso permanência de estudantes com deficiência visual na educação superior, por compreender o homem como uma pessoa relacional e assim um ser social que se desenvolve na relação com 
outros homens, caso seja cerceada essa relação entre as pessoas videntes e não videntes cria-se uma barreira no processo de desenvolvimento do não vidente.

Esta produção também se encontra lastreada na Escola Justa, construção teórica consolidada por François Dubet, cuja definição engloba tanto fatores vinculados à superação dos aspectos meritocráticos, às condições com as quais os estudantes se defrontam em seu cotidiano, as adversidades decorrentes da estrutura social, dentre outras. Para o autor, a Escola Justa, ao priorizar a justiça distributiva, pode ser concebida como a escola das oportunidades. Porém, esta concepção puramente meritocrática da justiça escolar se defronta com grandes dificuldades e, mesmo que aceitemos o princípio, fica claro que ele deve ser ponderado [...] (DUBET, 2004, p. 542)

O objetivo deste trabalho é analisar as pesquisas sobre acesso, permanência com ênfase no Atendimento Educacional Especializado de estudantes com deficiência visual nas produções da Revista de Educação Especial da Universidade Federal de Santa Maria (UFSM) no período de 2014 a 2019.

\section{Metodologia}

A metodologia aplicada desde uma perspectiva quanti-qualitativa, é revisão bibliográfica, centrada nos dados a partir das publicações disponibilizadas pela Revista de Educação Especial, da UFSM nos últimos cinco anos. As abordagens quanti-qualitativa se inter-relacionam, assim, integram qualidade e quantidade e superam limites que podem ocorrer nas abordagens separadas (SOUZA; KERBAUY, 2017).

Nos limites das palavras-chave ou descritores que puderam conduzir à localização de pesquisas que trataram do acesso e da permanência do estudante com deficiência visual no Ensino Superior e do atendimento educacional especializado, foram utilizadas as seguintes: Atendimento Educacional Especializado; Educação superior; Deficiência visual; Permanência na educação superior; Permanência; Deficiência e Inclusão na Educação Superior; registramos que o operador lógico utilizado para a seleção dos artigos foi o " $A N D$ ”. Os critérios de exclusão utilizados foram estabelecidos a partir de artigos que versassem acerca das palavras chave, mas não tratassem de deficiência visual, AEE na educação superior, educação superior, inclusão, permanência, artigos que embora versassem a temática, mas não relacionados a educação superior, artigos repetidos, dificuldades de aprendizagem, inserção no mercado de trabalho, psicoterapias, religião e negligencia parental. 
Foram capturados 519 artigos que aludiam as palavras chave informadas no quadro 1. Após as análises dos títulos, períodos das publicações e resumos, selecionamos aqueles que referenciaram a educação superior, a deficiência visual, o acesso a permanência e o atendimento educacional especializado. Com o recorte temporal a partir do ano de 2014 a 2019, constituímos o corpus teórico com 14 produções a serem analisadas.

Quadro 1 - Número de artigos com as Palavras-chave

\begin{tabular}{|l|r|}
\hline \multicolumn{1}{|c|}{ Palavras-chave } & $\mathrm{N}^{\mathrm{o}}$ de artigos \\
\hline Inclusão na educação superior & 39 \\
\hline Permanência na educação superior & 45 \\
\hline Deficiência visual & 74 \\
\hline Educação superior & 25 \\
\hline Permanência & 254 \\
\hline Deficiência & 48 \\
\hline Atendimento Educacional Especializado & 7 \\
\hline Educação superior $A N D$ deficiência visual & 5 \\
\hline Acesso $A N D$ permanência $A N D$ educação superior & 4 \\
\hline Inclusão na educação superior $A N D$ Atendimento educacional \\
especializado & 1 \\
\hline Educação superior $A N D$ deficiência $A N D$ Atendimento educacional \\
especializado
\end{tabular}

Fonte: elaborado pelos autores

\section{Resultados}

Explicitamos que no que concerne aos resultados fáticos, dentre as produções, foi identificada expressiva gama de trabalhos vinculados à educação básica. No entanto, ao se enfocar o acesso dos Estudantes com deficiência no Ensino Superior e o AEE, esta primeira busca, trouxe o resultado de uma única pesquisa, quando utilizamos descritores combinados.

Na sequência do presente levantamento de produções na Revista de Educação Especial da Universidade Federal de Santa Maria, inserimos o descritor Deficiência visual, e capturamos 
45 artigos dentre os artigos localizados, achamos trabalhos com temáticas relativas à educação inclusiva na educação básica, a usabilidade da LIBRAS no contexto da Educação Superior, aspectos correlatos ao ensino da disciplina de Química para estudantes com deficiência visual. Os achados que não se relacionavam a deficiência Visual foram descartados.

Outra palavra chave inserida visando a localização de trabalhos adicionais no âmbito definido para a busca supramencionada, foi "Educação Superior". Desta feita, o número de pesquisas identificadas, perfez um total de 74 itens. É fundante ressaltar que com tal palavra, foram disponibilizadas averiguações no campo da surdez/deficiência auditiva, autismo, surdocegueira, participação de estudantes com deficiência visual disciplina de Educação Física, Altas Habilidades/Superdotação, dentre outras.

Ressaltamos que em se tratando do Ensino Superior, foram localizados seis trabalhos com indício de que a abordagem fosse compatível com o propósito deste levantamento. Portanto, passa-se a tecer as considerações concernentes aos aspectos referentes a essas publicações

Quadro 2 - Artigos publicados com foco na inclusão das pessoas com deficiência visual na educação superior

\begin{tabular}{|c|c|c|c|}
\hline Ano & $\begin{array}{l}\text { TÍTULO } \\
\text { AUTOR }\end{array}$ & PALAVRAS-CHAVE & $\begin{array}{l}\mathbf{N}^{0} \quad \text { repetições } \\
\text { palavras-chave }\end{array}$ \\
\hline 2014 & $\begin{array}{l}\text { Desafios da implantação do atendimento } \\
\text { educacional especializado no Ensino Superior } \\
\text { Alexandra Ayach Anache, Sabrina Stella Maris } \\
\text { Rovetto, Regiane Alves de Oliveira }\end{array}$ & $\begin{array}{lr}\text { Atendimento } & \text { educacional } \\
\text { especializado } & A N D \\
\text { Educação Superior } & A N D \\
\text { Deficiência } & A N D \\
\text { Permanência } & \\
\end{array}$ & 9 \\
\hline 2014 & $\begin{array}{l}\text { Quando não se falava em inclusão: a história de vida } \\
\text { do primeiro advogado cego formado no Brasil } \\
\text { Bento Selau, Magda Floriana Damiani }\end{array}$ & Educação Superior & 2 \\
\hline 2015 & $\begin{array}{l}\text { Formação do professor do atendimento educacional } \\
\text { especializado: a Educação Especial em questão } \\
\text { Elisabeth Rossetto }\end{array}$ & $\begin{array}{l}\text { Atendimento Educacional } \\
\text { Especializado }\end{array}$ & 2 \\
\hline 2015 & $\begin{array}{l}\text { Educação Especial, Educação Inclusiva e Pedagogia } \\
\text { da Diversidade: Celebrar a diversidade! Exaltar a } \\
\text { tolerância! Notabilizar o respeito! Proclamar a } \\
\text { solidariedade! } \\
\text { Márcia Lise Lunardi-Lazzarin, Simoni Timm } \\
\text { Hermes }\end{array}$ & $\begin{array}{l}\text { Atendimento Educacional } \\
\text { Especializado }\end{array}$ & 0 \\
\hline 2015 & $\begin{array}{l}\text { Alunos com deficiência: investigação e análise das } \\
\text { condições de atendimento de um Instituto Federal de } \\
\text { Educação, Ciência e Tecnologia no Brasil } \\
\text { Cesar Gomes de Freitas, Cristina Maria Delou, } \\
\text { Helena Carla Castro }\end{array}$ & Educação Superior & 2 \\
\hline 2016 & $\begin{array}{l}\text { Meios de acesso à literatura para pessoas com } \\
\text { cegueira: Braille ou Áudio livro? }\end{array}$ & Deficiência visual & 2 \\
\hline
\end{tabular}

RPGE- Revista on line de Política e Gestão Educacional, Araraquara, v. 24, n. esp. 2, p. 1118-1136, set. 2020. e-ISSN: 1519-9029 


\begin{tabular}{|c|c|c|c|}
\hline & $\begin{array}{l}\text { Vivian Santos, Amanda Cristina dos Santos Pereira, } \\
\text { Paulo E Zorel, Ailton Barcelos da Costa, Maria } \\
\text { Amélia Almeida, Marcia Duarte }\end{array}$ & & \\
\hline 2016 & $\begin{array}{l}\text { Inclusão de estudante cego em curso de Análise e } \\
\text { Desenvolvimento de Sistemas de uma instituição } \\
\text { pública de ensino superior: um estudo de caso } \\
\text { Luciano Tadeu Esteves Pansanato, Luzia Rodrigues, } \\
\text { Christiane Enéas Silva }\end{array}$ & Permanência & 4 \\
\hline 2016 & $\begin{array}{l}\text { O convívio acadêmico: representações sociais de } \\
\text { alunos com Necessidades Educacionais Especiais } \\
\text { Zenilda Nogueira Sales, Ramon Missias-Moreira, } \\
\text { Edvaldo Souza Couto }\end{array}$ & Educação Superior & 2 \\
\hline 2016 & $\begin{array}{l}\text { Inclusão de estudantes com deficiência no ensino } \\
\text { superior: uma revisão sistemática } \\
\text { Rosamaria Reo Pereira, Simone Souza da Costa } \\
\text { Silva, Rosana Assef Faciola, Fernando Augusto } \\
\text { Ramos Pontes, Maély Ferreira Holanda Ramos }\end{array}$ & $\begin{array}{l}\text { Educação Superior } A N D \\
\text { Deficiência } A N D \text { Inclusão }\end{array}$ & 3 \\
\hline 2016 & $\begin{array}{l}\text { Um estudo sobre a realidade da inclusão de pessoas } \\
\text { com deficiência na educação superior no Paraná. } \\
\text { Hernestina da Silva Fiaux Mendes, Camen Célia B. } \\
\text { C. Bastos }\end{array}$ & $\begin{array}{l}\text { Educação Superior } A N D \\
\text { Acesso } A N D \text { Permanência }\end{array}$ & 5 \\
\hline 2018 & $\begin{array}{l}\text { Revisitando a Acessibilidade a partir do Modelo } \\
\text { Social da Deficiência: Experiências na Educação } \\
\text { Superior } \\
\text { Jackeline Susann Souza da Silva }\end{array}$ & $\begin{array}{l}\text { Educação Superior } A N D \\
\text { Acesso } A N D \text { Permanência }\end{array}$ & 2 \\
\hline 2018 & $\begin{array}{l}\text { Marcadores sociais da diferença: uma perspectiva } \\
\text { interseccional sobre ser estudante negro e deficiente } \\
\text { no Ensino Superior brasileiro } \\
\text { Vanessa Carolina Silva, Wilker Solidade Silva }\end{array}$ & $\begin{array}{l}\text { Educação Superior } A N D \\
\text { Deficiência }\end{array}$ & 3 \\
\hline 2018 & $\begin{array}{l}\text { Experiência de pessoas com deficiência no ensino } \\
\text { superior: um olhar sobre a vivência de } \\
\text { empoderamento e auto advocacia } \\
\text { Taísa Caldas Dantas }\end{array}$ & Educação Superior & 2 \\
\hline 2019 & $\begin{array}{l}\text { A narrativa de universitários cegos acerca de suas } \\
\text { experiências acadêmicas } \\
\text { Danielle Sousa Silva, Maristela Rossato, Erenice } \\
\text { Natalia Soares Carvalho }\end{array}$ & $\begin{array}{l}\text { Educação Superior AND } \\
\text { Acesso AND Permanência }\end{array}$ & 7 \\
\hline
\end{tabular}

Fonte: elaborado pelos autores

Passa-se a enfatizar, como ponto de partida, o trabalho localizado a partir da inserção da palavra-chave deficiência visual nesta produção. Destaque-se que o texto correspondente à pesquisa em análise, foi mencionado de passagem na introdução do levantamento bibliográfico ora levado a efeito. Seu título é: "Quando não se falava em inclusão: a história de vida do primeiro advogado cego formado no Brasil’". Os autores desta produção são Selau e Damiani (2014).

A pesquisa foi efetivada a partir da realização de entrevista com familiares e colegas de faculdade de Walkírio Ughini Bertoldo, consubstanciada também pelo método biográfico, baseando-se ainda em publicações de jornais impressos que deram ampla cobertura à história 
de Walkírio Bertoldo, que conforme a investigação ingressou no curso de Direito da Pontifícia Universidade Católica do Rio Grande do Sul (PUCRS).

Os autores afirmam que mesmo em tempos da busca pela inclusão, o ingresso de estudantes com deficiência na Educação Superior, ainda é digno de notabilização, conforme expresso neste trecho da publicação enfocada:

Recentemente, o site mundo vestibular, reproduzindo reportagem divulgada pelo jornal Zero Hora, do dia 18 de setembro de 2009, enalteceu a apresentação do trabalho de conclusão de curso do acadêmico de Letras/Espanhol da Universidade Federal de Santa Maria (UFSM), Rodrigo Gonçalves da Silva (SELAU; DAMIANI, 2014, p. 134).

De acordo com o veiculado, o acadêmico era o primeiro estudante cego a concluir a educação superior na UFSM, fato ocorrido em 2009. Os autores apontam nas considerações finais, o esmero e determinação de Walkírio Ughini Bertoldo, mas sobretudo, enfatizam a ação do longínquo ano de 1957, enquanto momento distinto no que tange à abertura de horizontes formativos para o estudante com deficiência visual no Ensino Superior. De sorte, que conforme a explicitação dos dados contidos na investigação, é evidenciado enquanto elemento que se vincula à inclusão, o caráter meritocrático, ainda tão marcante na caminhada acadêmica dos estudantes com deficiência visual brasileiros.

Na sequência apresentamos alguns trabalhos que relatam como esta inclusão acontece na educação superior. Iniciamos com Freitas, Delou e Castro (2015) que compararam o atendimento realizado aos estudantes com deficiência em um instituto federal tecnológico da região norte e uma universidade na região sudeste. O instituto federal tecnológico - IFECT era composto por quatro campis. Quanto à universidade, não foi informada se é multicampi. No IFECT 30 alunos com deficiência eram atendidos nos núcleos, enquanto na universidade 130 eram atendidos. As deficiências declaradas foram surdez, cegueira, baixa visão, síndromes e transtornos, dificuldades de locomoção e retardo mental. As autoras observaram falta de recursos materiais, tecnologias acessivas limitando os serviços oferecidos. As ações acadêmicas e pedagógicas são limitadas e insuficientes para garantir um atendimento pleno e eficaz no que se refere à educação superior, acesso e permanência compilamos a pesquisa de Mendes e Bastos (2016), desenvolvida no município de Umuarama, Estado do Paraná que tem por título: “Um estudo sobre a realidade da inclusão de pessoas com deficiência na educação superior".

A investigação revela as implicações que incidem na formação do estudante com deficiência na educação superior, em instituição do aludido nível educacional, a partir do preconceito e falta de material no desenvolvimento da formação acadêmica. Aponta ainda, as 
contribuições de caráter familiar para a consolidação da formação dos discentes na citada etapa educacional.

Portanto, em que pese o relevante escopo da pesquisa, "ao desvelar elementos constitutivos enquanto óbices para tal formação, a averiguação não responde à especificidade relativa ao caminhar acadêmico do estudante com deficiência visual no cerne da universidade" (FREITAS; DELOU; CASTRO, 2015, p. 773). Em relação aos obstáculos nos IFECTs a pesquisa as autoras encontraram a mudança de coordenadores dos núcleos.

Com referência a universidade federal, há recursos financeiros suficientes para a realização das ações do núcleo visando diminuir barreiras e garantir a acessibilidade arquitetônica, pedagógicas, comunicacional e outras. Ao se efetivar este levantamento, também se deparou com a Pesquisa conduzida por Dantas (2018), cujo desenvolvimento, deu-se com base no título: "Experiência de pessoas com deficiência no ensino superior: um olhar sobre a vivência de empoderamento e auto advocacia".

Nesta produção, a autora traz componentes que demonstram a importância do acesso ao Ensino Superior, enquanto fator fundante no campo da autonomia e independência dos estudantes que constroem a trajetória até ao referido nível de ensino. Para tanto, Dantas toma como referencial os estudos culturais, lastreando a investigação na abordagem qualitativa com estudantes com deficiência da Universidade Federal da Paraíba. Todavia, considerada a finalidade da busca aqui proposta, registramos que a investigação em tela, não se coaduna aos objetivos anunciados para este levantamento.

No que se refere às palavras educação superior, acesso e permanência, compilamos a pesquisa de Mendes e Bastos (2016), desenvolvida no município de Umuarama, Estado do Paraná que tem por título: "Um estudo sobre a realidade da inclusão de pessoas com deficiência na educação superior".

A investigação revela as implicações que incidem na formação do estudante com deficiência na educação superior, em instituição do aludido nível educacional, a partir do preconceito e falta de material no desenvolvimento da formação acadêmica. Aponta ainda, as contribuições de caráter familiar para a consolidação da formação dos discentes na citada etapa educacional.

Ainda está o trabalho: "O convívio acadêmico: representações sociais de alunos com Necessidades Educacionais Especiais”, pesquisa de Sales, Missias-Moreira e Couto (2016), com o método de estudo de caso, descritivo, exploratório e qualitativo, com aporte teórico alicerçado na teoria das representações sociais, lócus universidade estadual da Bahia. Os participantes foram 11 alunos, 8 deles com deficiência visual, dois com deficiência física e uma 
deficiência auditiva. Um dos resultados da pesquisa foi a verificação que os professores e pares desses acadêmicos não estão preparados para a inclusão da diversidade na universidade.

Ao se analisar o trabalho "Desafios da implantação do atendimento educacional especializado no Ensino Superior” de Anache, Rovetto e Oliveira, foi possível constatar que se trata de uma pesquisa densa. Desenvolvida a partir da técnica da conversação, a averiguação englobou 238 sujeitos nos limites dos corpos docente e discente, tratando da disponibilidade da tecnologia assistiva e seu impacto no Atendimento educacional para estudantes com necessidades Educacionais Especiais. Como o próprio título enfatiza o AEE na educação superior é um desafio e se constitui de vários atores. As autoras identificaram 08 estudantes deficientes que recebem o AEE: 2 com surdez moderada, 1 cego, 2 com deficiência física, 1 com baixa visão e 2 com transtornos mentais.

Os atendimentos consistiram prioritariamente na disponibilização de equipamentos, softwares, adaptação de materiais didáticos, orientações pedagógicas aos alunos/as e aos seus professores/as, além do encaminhamento para os atendimentos psicológicos disponibilizados nesta (ANACHE; ROVETTO; OLIVEIRA, 2014, p. 309). Essa pesquisa é uma das pioneiras que tratam do AEE na educação superior e mostra que esse atendimento é um fator que auxilia a permanência do estudante com deficiência nesse nível de educação.

No entanto, em face da abrangência da pesquisa no que tange às características dos estudantes e dos profissionais que atuam na área retro mencionada, não oportunizou o aprofundamento nesta, vez que não teve como diretriz estudar conforme especificidades, as circunstâncias nas quais se encontra o desenvolvimento das condições dos serviços destinados ao público definido, conforme o propósito desta produção, qual seja, o acesso do estudante com deficiência visual no Ensino Superior.

Existe um grupo de pesquisas que se julga pertinente no presente levantamento, sobre como acontece esta inclusão e os recursos utilizados, começando pela investigação que traz por título: “Meios de acesso à literatura para pessoas com cegueira: Braille ou Audiolivro?”. Isto porque tal indagação tem suscitado diversos debates no que diz respeito a melhor forma de acesso às publicações pelos estudantes com deficiência visual. Quanto aos pesquisadores que tomaram tal incumbência, estes são: Santos et al. (2016).

A pesquisa definida como quanti-qualitativa, foi desenvolvida por meio da realização de entrevistas, compondo o número de estudantes com deficiência em um total de cinco, sendo essas pessoas com cegueira congênita ou adquirida. Importa também explicitar que os estudantes tinham no período da realização da investigação acesso aos audiolivros e produções em braile por intermédio de instituições de cunho público e privado. A investigação concluiu 
que dentre os entrevistados, 80 por cento declaram preferência por acessar publicações, via escrita braile.

A averiguação informa ainda que dentre as restrições concernentes à mencionada escrita, se destacam o peso dos livros e a letargia no desempenho nos atos de leitura e escrita. Já no que tange ao acesso ao audiolivro, os principais óbices, são de ordem relativa à gramática e ortografia, questões que podem implicar em redução nos aspectos financeiros e econômicos, vez que esses limites impostos pela usabilidade do audiolivro, interferem no rol de oportunidades no mundo do trabalho para a pessoa com deficiência visual.

Destarte, se trata de pesquisa que aborda preocupação no contexto atual, seja esta por meio dos profissionais que atuam na área do atendimento ao público em tela, seja do ponto de vista das próprias pessoas com deficiência, que no limite de tal preocupação, em determinadas circunstâncias precisam optar pela forma disponibilizada pela unidade de produção, em prejuízo da sua preferência, circunstância que decorre ainda da escassez de produções pela via impressa ou do audiolivro.

A pesquisa que se insere no rol da busca do presente levantamento, versa a respeito da Narrativa de Universitários Cegos e suas Experiências Acadêmicas. A produção foi conduzida pelas autoras Sousa Silva, Rossato e Carvalho (2019). Os participantes foram dois estudantes cegos, em uma universidade do Distrito Federal. Após a abordagem por meio da qual se buscou trazer a gênese relativa à inclusão do estudante com deficiência visual no Ensino Superior, nesta última pesquisa analisada com a palavra-chave Educação Superior, identificamos a ênfase conferida à expansão no número de estudantes na mencionada etapa da formação acadêmica. A produção de caráter narrativo informa ainda que os discentes desconhecem seus direitos às melhores condições no âmbito da promoção da acessibilidade. Circunstância que implica diretamente na tomada de medidas tendentes à garantia da adequação curricular.

Quando introduzida a palavra Deficiência visual, por se constituir em identificação no presente levantamento, ressalta-se a pesquisa: “Inclusão de estudante cego em curso de Análise e Desenvolvimento de Sistemas de uma instituição pública de ensino superior: um estudo de caso”. Quanto a autoria, são responsáveis pela produção: Pansanato, Rodrigues e Silva (2016).

A investigação de cunho longitudinal na modalidade Estudo de Caso, trouxe de maneira enfática as adaptações implementadas para viabilizar o melhor aproveitamento do curso na área de tecnologia pelo estudante com deficiência visual. Outro ponto abordado na averiguação, foi a detecção de algumas lacunas, presentes na formação docente.

Ainda assim, considerada a totalidade do período da pesquisa, os autores concluíram que o objetivo do estudante ao optar por um curso na área computacional, atingiu suas 
finalidades, tendo encerrado o curso com adequada substituição dos aspectos de ordem visual, exatamente pelas adequações concretizadas pelos docentes.

E "Revisitando a Acessibilidade a partir do Modelo Social da Deficiência: Experiências na Educação Superior” da autora Silva (2018) identificou acessibilidades ou barreiras que enfrentam os estudantes que visam ingressar na universidade e também aquelas que se apresentam pós ingresso. A autora entende que a acessibilidade é um direito. A pesquisa é um estudo de caso, pesquisa semiestruturada e técnica shadowing no qual o pesquisador se torna a sombra do participante, acompanha-o em todas as atividades educacionais. Silva (2018, p. 202) utilizou quatro tipos de acessibilidade: (1) acessibilidade arquitetônica e estrutural; (2) acessibilidade atitudinal; (3) acessibilidade informacional e comunicacional e (4) acessibilidade pedagógico-curricular. Seis participantes tomaram parte na pesquisa, três homens e 3 mulheres, dois deles eram surdos, dois cegos, um com deficiência física e uma paralisia cerebral.

Os resultados da pesquisa demonstraram a barreira atitudinal como a mais urgente para ser resolvida, pois dela resultam outras barreiras. "As experiências dos estudantes com deficiência revelam que a cultura universitária cria ambientes incapacitantes para as pessoas com deficiência” (SILVA, 2018, p. 210). Para equalizar essa condição a autora propõe o modelo social da deficiência que "compreender a acessibilidade muito mais que um direito, mas como um valor cultural associado a um movimento pessoal-coletivo de busca por atitudes favoráveis que equilibrem diferenças humanas e inerentes liberdades". E nesse sentido criar uma cultura universitária que aceite as diversidades existentes no ambiente educativo e o ingresso e a permanência são responsabilidade de todos.

Quando a palavra chave foi Educação Superior e Inclusão, foram localizadas publicações vinculadas à Educação Superior de Estudantes com Deficiência, A Atuação de Intérprete e a LIBRAS na Educação Superior, Atendimento ao Estudante com Surdocegueira no Ensino Regular, para além de alguns artigos já analisados nesta produção. Porém, não houve a localização via indicação dos títulos, de outros trabalhos com origem na Educação superior e que ao mesmo tempo, expressassem a temática a esse nível de ensino por estudantes com deficiência visual.

Lunardi-Lazzarin e Hermes (2015) e Rossetto (2015) trataram da formação dos professores para o AEE. As primeiras relataram: Atendimento Educacional Especializado no Brasil: relatos da experiência profissional de professores e sua formação, no curso de extensão e aperfeiçoamento dos professores em AEE em uma universidade do Rio Grande do Sul, tecem a inclusão como diversidade e um direito e um desafio.

Rossetto (2015, p. 114) em seu estudo bibliográfico e documental constatou que o AEE: 
assume centralidade nas proposições de apoio à educação ao ser promovido no discurso de sucesso individual pela inclusão e ao ser colocado como a garantia de viabilidade desse processo. Além disso, ele não tem ênfase no ensino e na aprendizagem, mas no fornecimento de aparato técnico, bem como na formação da capacidade de uso desses recursos. Portanto, esse atendimento está no bojo das ações que atualizam a educação de acordo com as expectativas do homem com capacidade técnica e habilidades imediatas para o processo produtivo no mundo globalizado.

Nesse sentido o AEE é entendido como algo que resolverá as questões deficitárias dos estudantes com deficiência em todos os níveis de educação e no que tange a formação, a autora a percebe como aligeirada e de acordo com os princípios da educação neoliberal. Entendemos o AEE como uma alternativa junto aos demais processos de permanência, mas ele não é a permanência em si. Retomando a formação para a oferta desse atendimento, Rossetto (2015) enfatiza que, devido ser um processo aligeirado o embasamento teórico por vezes é feito com fundamento limitado e imediato, tal qual a necessidade da cadeia produtiva, registramos que essa formação se dá a partir da educação a distância. É necessário discutir a formação do professor e o que realmente é o AEE.

Finalmente, ao se inserir a palavra-chave Ingresso, Permanência, Educação Superior, o único artigo encontrado, versa acerca da evasão de estudantes com surdez na Educação Superior. Destarte, o número de produções de ordem específica a propósito do objetivo do presente levantamento, se apresentou de maneira bastante diminuta, consideradas as mais diversas formas por meio da diversidade presente na abrangência das palavras-chave inseridas.

Nesta mesma linha de educação superior e deficiência encontramos o documento: "Marcadores sociais da diferença: uma perspectiva interseccional sobre ser estudante negro e deficiente no Ensino Superior brasileiro", escrito por Silva e Silva (2018), pesquisa bibliográfica, exploratória e análise qualitativa, foco de análise como marcador, raça, cor e deficiência. O lócus da pesquisa foi o banco de teses e dissertações da Capes, 2012 a 2017 e o número dos estudantes matriculados com esses marcadores nos anos 2010 e 2015. Os autores perceberam um aumento nas matrículas do público pesquisado (negros, deficientes, quilombolas), esse é um reflexo, segundo eles, das políticas de ações afirmativas positivas dentro das instituições de educação superior, como resultado da pesquisa em reconhecer as particularidades dos estudantes e propor estratégias de inclusão e fortalecer os vínculos desses estudantes.

Com os termos Educação superior, deficiência e inclusão capturamos um artigo intitulado: "Inclusão de estudantes com deficiência no ensino superior: uma revisão 
sistemática", de Pereira et al. (2016), teve como objetivo a análise de produções científicas relacionadas a inclusão de estudantes com deficiência na educação superior. O lócus da pesquisa foi a na base de dados dos Periódicos da Coordenação de Aperfeiçoamento de Pessoal de Nível Superior - CAPES, no período de 2003 e 2013. Metodologia qualitativa. Foi possível perceber, conforme os autores, que a inclusão desses estudantes embora amparado por leis nem sempre há o favorecimento para a inclusão ampla. Entendemos com isso que por vezes a legislação ampara, mas a instituição excluí. Essa temática percebemos ser recente nesse nível de educação motivo pelo qual exige maiores aprofundamentos.

\section{Considerações finais}

A análise das produções, para o desenvolvimento da presente investigação, demonstrou a relevância desta temática, seja pelo foco da averiguação, seja por se explicitar por meio da mesma, o crescente número de estudantes com deficiência no Ensino superior, ainda mais em razão da dinâmica transformadora a partir das ferramentas tecnológicas inovadoras com aplicação no contexto educacional.

O fato de encontrarmos 14 documentos, com foco no objeto de pesquisa, em apenas uma revista especializada e segundo os critérios e inclusão determinados, indica que existe um crescente interesse por este objeto de pesquisa embora ainda esteja em desenvolvimento. Verificamos que dentre os diversos autores dos trabalhos que versam sobre a temática inclusão na educação superior, concretamente quatro trataram da permanência do estudante com deficiência visual nesse nível de educação.

Em relação ao foco da pesquisa, os estudantes com deficiência visual na educação superior, constatamos que ainda precisa ser mais investigado em pesquisas futuras (PEREIRA et al., 2016; e outros), em temáticas diversas sobre como realmente ocorre essa inclusão, limitações e desafios. O artigo que versou sobre a história de Walkírio Ughini Bertoldo, que por meios próprios, deixa claro que foi o primeiro estudante cego a ter essa escolarização, porém as pesquisas demonstram que são muitos os acadêmicos com deficiência visual na educação superior hoje em dia (SILVA; SILVA, 2018). Sobre isso é evidenciado, enquanto elemento que se vincula à inclusão, o caráter meritocrático ainda tão marcante na caminhada acadêmica dos estudantes brasileiros com deficiência visual.

Observamos nos trabalhos analisados que embora estes acadêmicos estejam presentes nas Universidades brasileiras se constata importante falta de recursos materiais e tecnologias acessivas limitando os serviços oferecidos. 
Fica evidenciado que a importância da disponibilidade da tecnologia assistiva no trabalho junto às pessoas com deficiência visual na educação superior e seu impacto no atendimento educacional para estudantes.

Se constata a precariedade das circunstâncias nas quais se encontra o desenvolvimento das condições dos serviços destinados ao público definido na educação superior, embora existam núcleos de acessibilidade.

De outro lado, os professores e pares desses acadêmicos, parece evidente que não estão preparados para a inclusão da diversidade na universidade, com um longo caminho a ser percorrido ainda, apesar dos muitos dispositivos legais existentes.

Dos dois trabalhos achados sobre formação de professores para o atendimento educacional especializado, fica entendido como algo que resolverá as questões deficitárias dos estudantes com deficiência em todos os níveis de educação e, no que tange a formação, se percebe como aligeirada.

Portanto, esse estudo mostrou a relevância para novos encaminhamentos acerca do processo de inclusão aliado ao AEE nas instituições de educação superior. Os estudos para o público investigado ainda são insuficientes e necessitam de maiores aprofundamentos.

Percebemos, de acordo com Rossetto (2016), que a formação para o AEE ainda é incipiente e de forma aligeirada e entrelaçados com as políticas neoliberais.

\section{REFERÊNCIAS}

ANACHE, A. A.; ROVETTO, S. S. M.; OLIVEIRA, R. A. de. Desafios da implantação do atendimento educacional especializado no Ensino Superior. Revista Educação Especial, Santa Maria, p. 299-312, jun. 2014. Disponível em:

https://periodicos.ufsm.br/educacaoespecial/article/view/9037. Acesso em: 25 jun. 2019. DOI: http://dx.doi.org/10.5902/1984686X9037

BIZELLI, J. L.; SEBASTIAN-HEREDERO, E. Educação e inovação: o desafio da escola brasileira. Revista Tendências Pedagógicas. Madrid, UCM, v. 28, p. 55-66, 2016. Disponível em: https://revistas.uam.es/tendenciaspedagogicas/article/download/3801/4948. Acesso em: 25 jun. 2019.

BRASIL. Lei n. 13.146, de 6 de julho de 2015. Institui a Lei Brasileira de Inclusão da Pessoa com Deficiência (Estatuto da Pessoa com Deficiência). Brasília, 7 jul. 2015. Disponível em: http://www.planalto.gov.br/ccivil_03/_ato2015-2018/2015/lei/113146.htm. Acesso em: 10 jun. 2020.

CAIADO, K. R. M. Aluno deficiente visual na escola: lembranças e depoimentos.

Campinas: Autores Associados, 2003. 
DANTAS, T. C. Experiência de pessoas com deficiência no ensino superior: um olhar sobre a vivência de empoderamento e autoadvocacia. Revista Educação Especial, Santa Maria, p. 525-538, ago. 2018. ISSN 1984-686X. Disponível em:

https://periodicos.ufsm.br/educacaoespecial/article/view/26760. Acesso em: 25 jun. 2019. DOI: http://dx.doi.org/10.5902/1984686X26760

DUBET, F. O que é uma escola justa? Cadernos de Pesquisa, São Paulo, v. 34, n. 123, p. 539-555, 2004. Disponível em: http://www.scielo.br/pdf/cp/v34n123/a02v34123.pdf. Acesso em: 3 ago. 2020.

FRANÇA, T. H. Modelo Social da Deficiência: uma ferramenta sociológica para a emancipação social. Lutas Sociais, São Paulo, v. 17, n. 31, p. 59-73, dez. 2013. ISSN 25263706. Disponível em: https://revistas.pucsp.br/ls/article/view/25723/18359. Acesso em: 9 ago. 2019.

FREITAS, C. G. de; DELOU, C. M.; CASTRO, H. C. Alunos com deficiência: investigação e análise das condições de atendimento de um Instituto Federal de Educação, Ciência e Tecnologia no Brasil. Revista Educação Especial, Santa Maria, p. 765-778, set. 2015. ISSN 1984-686X. Disponível em: https://periodicos.ufsm.br/educacaoespecial/article/view/15747. Acesso em: 25 jun. 2019. DOI: http://dx.doi.org/10.5902/1984686X15747

INEP. Censo Da Educação Superior. 2014. Disponível em:

http://portal.inep.gov.br/web/guest/sinopses-estatisticas-da-educacao-superior. Acesso em:10 ago. 2020.

JANNUZZI, G. M. A educação do deficiente no Brasil: dos primórdios ao início do século XXI. 2. ed. Campinas: Autores Associados, 2006.

LUNARDI-LAZZARIN, M. L.; HERMES, S. T. Educação Especial, Educação Inclusiva e Pedagogia da Diversidade: Celebrar a diversidade! Exaltar a tolerância! Notabilizar o respeito! Proclamar a solidariedade! Revista Educação Especial, Santa Maria, p. 531-544, set. 2015. ISSN 1984-686X. Disponível em:

https://periodicos.ufsm.br/educacaoespecial/article/view/18802. Acesso em: 25 jun. 2019. doi: http://dx.doi.org/10.5902/1984686X18802

MAZZOTTA, M. J. S. Educação especial no Brasil: história e políticas públicas. 5. ed. São Paulo: Cortez, 2005.

PANSANATO, L. T. E.; RODRIGUES, L.; SILVA, C. E. Inclusão de estudante cego em curso de Análise e Desenvolvimento de Sistemas de uma instituição pública de ensino superior: um estudo de caso. Revista Educação Especial, Santa Maria, p. 471-486, ago. 2016. ISSN 1984-686X. Disponível em:

https://periodicos.ufsm.br/educacaoespecial/article/view/17106. Acesso em: 25 jun. 2019. doi: http://dx.doi.org/10.5902/1984686X17106

PEREIRA, R. R. et al. Inclusão de estudantes com deficiência no ensino superior: uma revisão sistemática. Revista Educação Especial, Santa Maria, v. 29, n. 54, p. 147-160, mar. 2016. ISSN 1984-686X. Disponível em: https://periodicos.ufsm.br/educacaoespecial/article/view/19898. Acesso em: 25 jun. 2019. DOI: http://dx.doi.org/10.5902/1984686X19898 
ROSSETTO, E. Formação do professor do atendimento educacional especializado: a Educação Especial em questão. Revista Educação Especial, Santa Maria, p. 103-116, dez. 2015. ISSN 1984-686X. Disponível em:

https://periodicos.ufsm.br/educacaoespecial/article/view/13367. Acesso em: 25 jun. 2019. DOI: http://dx.doi.org/10.5902/1984686X13367

SALES, Z. N.; MISSIAS-MOREIRA, R.; COUTO, E. S. O convívio acadêmico: representações sociais de alunos com Necessidades Educacionais Especiais. Revista Educação Especial, Santa Maria, v. 29, n. 55, p. 295-308, ago. 2016. ISSN 1984-686X. Disponível em: https://periodicos.ufsm.br/educacaoespecial/article/view/14275. Acesso em: 25 jun. 2019. DOI: http://dx.doi.org/10.5902/1984686X14275

SANTOS, V. et al. Meios de acesso à literatura para pessoas com cegueira: Braille ou Áudiolivro? Revista Educação Especial, Santa Maria, v. 29, n. 55, p. 337-350, ago. 2016. ISSN 1984-686X. Disponível em: https://periodicos.ufsm.br/educacaoespecial/article/view/10522. Acesso em: 25 jun. 2019. DOI: http://dx.doi.org/10.5902/1984686X10522

SELAU, B.; DAMIANI, M. F... Quando não se falava em inclusão: a história de vida do primeiro advogado cego formado no Brasil. Revista Educação Especial, Santa Maria, v. 27, n. 49, p. 417-430, jun. 2014. ISSN 1984-686X. Disponível em:

https://periodicos.ufsm.br/educacaoespecial/article/view/9633. Acesso em: 25 jun. 2019. DOI: http://dx.doi.org/10.5902/1984686X9633

SILVA, J. S. S. da. Revisitando a Acessibilidade a partir do Modelo Social da Deficiência: Experiências na Educação Superior. Revista Educação Especial, Santa Maria, v. 31, n. 60, p. 197-214, mar. 2018. ISSN 1984-686X. Disponível em:

https://periodicos.ufsm.br/educacaoespecial/article/view/23590. Acesso em: 25 jun. 2019.

DOI: http://dx.doi.org/10.5902/1984686X23590

SILVA, V. C.; SILVA, W. S. Marcadores sociais da diferença: uma perspectiva interseccional sobre ser estudante negro e deficiente no Ensino Superior brasileiro. Revista Educação Especial, Santa Maria, v. 31, n. 62, p. 569-586, ago. 2018. ISSN 1984-686X. Disponível em: https://periodicos.ufsm.br/educacaoespecial/article/view/30948. Acesso em: 25 jun. 2019. DOI: http://dx.doi.org/10.5902/1984686X30948

SOUSA SILVA, D.; ROSSATO, M.; SOARES CARVALHO, E. N. A narrativa de universitários cegos acerca de suas experiências acadêmicas. Revista Educação Especial, Santa Maria, v. 32, p. 1-20, abr. 2019. ISSN 1984-686X. Disponível em: https://periodicos.ufsm.br/educacaoespecial/article/view/32390. Acesso em: 25 jun. 2019. DOI: http://dx.doi.org/10.5902/1984686X32390

SOUZA, K. R.; KERBAUY, M. T. M. Abordagem quantiqualitativa: superação da dicotomia quantitativa-qualitativa na pesquisa em educação. Educação e Filosofia, Uberlândia, v. 31, n. 61, p. 21-44, 2017. 


\section{Como referenciar este artigo}

COSTA, J. A.; MADRUGA, R. S.; ANACHE, A. A.; SEBASTIAN-HEREDERO, E. Desafios e perspectivas do estudante com deficiência visual na educação superior: análise da produção científica. Revista on line de Política e Gestão Educacional, Araraquara, v. 24, n. esp. 2, p. 1118-1136, set. 2020. e-ISSN: 1519-9029.DOI: https://doi.org/10.22633/rpge.v24iesp2.14338

Submetido em: 30/04/2020

Revisões requeridas em: 26/06/2020

Aprovado em: 30/07/2020

Publicado em: 30/09/2020 